\title{
Proceeding
}

9th INSHS International Christmas Sport Scientific Conference, 4-6 December 2014. International Network of Sport and Health

Science. Szombathely, Hungary

\section{Body segments cooperation during forehand stroke production in young and adult tennis players}

\author{
ANNA ZUŠA ${ }^{1}$, JĀNIS LANKA ${ }^{2}$, ANDREI VAGIN ${ }^{3}$, ANTONIO CICCHELLA ${ }^{4}$ \\ ${ }^{1}$ Kinesiology research laboratory, Latvian Academy of Sport Education, Riga, Latvia \\ 2 Department of biomechanics and informatics, Latvian Academy of Sport Education, Riga, Latvia \\ ${ }^{3}$ Department of biomechanics, Russian State University of Physical Culture, Sport, Tourism and Youth, Moscow, \\ Russia \\ ${ }^{4}$ Biomechanics laboratory, Bologna State University, Bologna, Italy
}

\begin{abstract}
Zuša, A., Lanka, J., Vagin, A., \& Cicchella, C. (2015). Body segments cooperation during forehand stroke production in young and adult tennis players J. Hum. Sport Exerc., 9(Proc1), pp.S161-S168. The purpose of the study was to investigate biomechanical characteristics of the forehand stroke production in adult and young tennis players, such as body segments cooperation, separation angle ( $\mathrm{x}$-factor) and max speed of a racquet. Kinematic data was collected with an optoelectronic motion capture system Qualisys. Participants in the experiment were 6 mid-level adult tennis players (age 19.5 \pm 2.3 years, weight $66.8 \pm 7.7 \mathrm{~kg}$, height $170.5 \pm 7.8 \mathrm{~cm}$, sports experience $13.2 \pm 1.7$ years) and 4 young tennis players (age $11 \pm 0.6$ years, weight $43.5 \pm 4.8 \mathrm{~kg}$, height $156.3 \pm 4.8 \mathrm{~cm}$, sports experience $5 \pm 0.5$ years). The task of the motion was to carry out 3 forehand strokes for 3 times, the position of the feet and type of stance was not regulated. Results showed that racquet speed during forehand follow through phase, is significantly higher in adult players. Adult athletes have significantly higher $x$-factor values, which indicates that they more effectively implement muscle-tendon complex pre-stretching principle during backswing and forward swing phase. As well as adults, young tennis players also perform principle of sequential action of body segments during the stroke production, according to their technical skills and level of training. Key words: KINEMATICS, XFACTOR, MUSCLE-TENDON COMPLEX PRE-STRETCHING, MAX SPEED OF A RACQUET, BODY SEGMENTS INTERACTION.
\end{abstract}

Corresponding author. Latvian Academy of Sport Education, Kinesiology Research laboratory, Brivibas gatve 333, Riga, LV1006, Latvija

E-mail: anna.zusa@Ispa.lv

9th INSHS International Christmas Sport Scientific Conference, 4-6 December 2014. International Network of Sport and

Health Science. Szombathely, Hungary.

JOURNAL OF HUMAN SPORT \& EXERCISE ISSN 1988-5202

(c) Faculty of Education. University of Alicante

doi:10.14198/jhse.2015.10.Proc1.01 


\section{INTRODUCTION}

Modern tennis is characterized by high dynamics and pace of the game, which increases each year. Therefore demands are rising on athletes' technical, tactical and physical preparedness. It stimulates the need for serious research.

Many studies are devoted to the investigation of adult tennis player stroke technique improvement, much less to study the problem of young tennis players' technical preparedness. The most studied stroke from biomechanical view point is a serve (Knudson \& Elliott, 2003), because this is the only stroke which is executed from statical position, the performance efficiency depends only from an athlete. Other strokes production investigation is more complicated, because all of them are being performed during the game situations and a lot of factors could affect the performance of the stroke. However, scientists try to simulate game situations in laboratory conditions or find any solutions for collecting experimental data on tennis court (Elliott et al., 2003; Ivancevic et al., 2011; Kopsic Segal, 2003; Rota et al., 2012). The most useful stroke during a game and practice usually is a forehand (Knudson and Blackwell, 2000; Zusa et al., 2010). During last 30 years forehand stroke biomechanics has changed, because of the equipment modification and the increasing tempo of the game. All these facts created an interest for us to study and analyze forehand stroke production differences between adult and young tennis players, to find a way for more effective stroke improvement in young athletes.

Aim of the research was to investigate biomechanical characteristics of the forehand stroke production for adult and young tennis players, such as body segments interaction and cooperation, separation angle ( $x$ factor) and max velocity of the racquet.

\section{MATERIAL AND METHODS}

In the experiment participated 6 mid-level adult tennis players (sports experience $13.2 \pm 1.7$ years, age $19.5 \pm 2.3$ years, height $170.5 \pm 7.8 \mathrm{~cm}$, weight $66.8 \pm 7.7$ ), and 4 young tennis players (sports experience $5 \pm 0.5$ years, age $11 \pm 0.6$ years, height $156.3 \pm 4.8 \mathrm{~cm}$, weight $43.5 \pm 4.8 \mathrm{~kg}$ ). All participants were competitive. The task of the motion was to carry out 3 forehand strokes for 3 times, the position of the feet and type of stance was not regulated. Kinematic data was collected with an optoelectronic motion capture system Qualisys (Sweden) with 8 high speed camera, filming frequency was set to $250 \mathrm{fs}$, data analysis performed with Qualisys Track Manager (QTM) package. Reflective markers were attached to the subject (20 landmarks) and to the racquet (6 landmarks). 27 forehands in each group (total $n=54$ strokes) were selected for the data analysis.

\section{RESULTS}

Significant differences $(\alpha<0.01)$ and correlation $(r=0,739$ only for adults) were found between values of separation angle ( $x$-factor) and generated maximal velocity of the racquet. Specialists consider interaction of upper and lower body segments (the $x$-factor is one the indicators) as a very important index of technical skills in stroke movement production. The research showed that at the beginning of the racquet forward swing, as well as in follow through phase (Fig. 1), the separation angle between hip and shoulder zone axis ( $\mathrm{x}$-factor) is statistically significantly greater for adult group players: $27.0 \pm 2.2^{\circ}$ for adults and $17.8 \pm 1.5^{\circ}$ for young players (table 1), that confirms their skill of using the mechanic properties of muscles, tendons and ligaments for increasing the efficiency of the stroke. 
Table 1. Values of $\mathrm{x}$-factor and maximal velocity of the racquet and body segments during forward swing and follow through phase

\begin{tabular}{llll} 
& $\begin{array}{c}\text { Adult tennis players } \\
(\text { strokes } \mathrm{n}=27)\end{array}$ & $\begin{array}{c}\text { Young tennis players } \\
\text { (strokes } \mathrm{n}=27)\end{array}$ & \\
\hline X-factor (separation angle) & $27.0 \pm 2.2^{\circ}$ & $17.8 \pm 1.5^{\circ}$ & $a<0.01$ \\
Max velocity of the racquet & $23.45 \pm 1.65 \mathrm{~m} / \mathrm{s}$ & $16.12 \pm 0.60 \mathrm{~m} / \mathrm{s}$ & $a<0.01$ \\
Velocity of wrist & $6.07 \pm 0.5 \mathrm{~m} / \mathrm{s}$ & $3.40 \pm 0.21 \mathrm{~m} / \mathrm{s}$ & $a<0.01$ \\
Velocity of elbow & $3.6 \pm 0.18 \mathrm{~m} / \mathrm{s}$ & $1.74 \pm 0.12 \mathrm{~m} / \mathrm{s}$ & $a<0.01$ \\
Velocity of shoulder & $1.42 \pm 0.08 \mathrm{~m} / \mathrm{s}$ & $0.87 \pm 0.07 \mathrm{~m} / \mathrm{s}$ & $a<0.01$ \\
\hline
\end{tabular}

The maximal velocity of the racquet at the end of forward swing phase and during beginning of follow through phase is significantly greater for adults. For adult players it was in average $23.45 \pm 1.65 \mathrm{~m} / \mathrm{s}$, but for young players $16.12 \pm 0.60 \mathrm{~m} / \mathrm{s}$, velocity of wrist for adults $6.07 \pm 0.5 \mathrm{~m} / \mathrm{s}$ and for young $3.40 \pm 0.21$ $\mathrm{m} / \mathrm{s}$, velocity of elbow for adults $3.6 \pm 0.18 \mathrm{~m} / \mathrm{s}$ and for young $1.74 \pm 0.12 \mathrm{~m} / \mathrm{s}$, velocity of shoulder for adults $1.42 \pm 0.08 \mathrm{~m} / \mathrm{s}$ and for young tennis players $0.87 \pm 0.07 \mathrm{~m} / \mathrm{s}$ respectively. All referenced values were significantly higher for adults $\alpha<0.01$ (table 1 ).

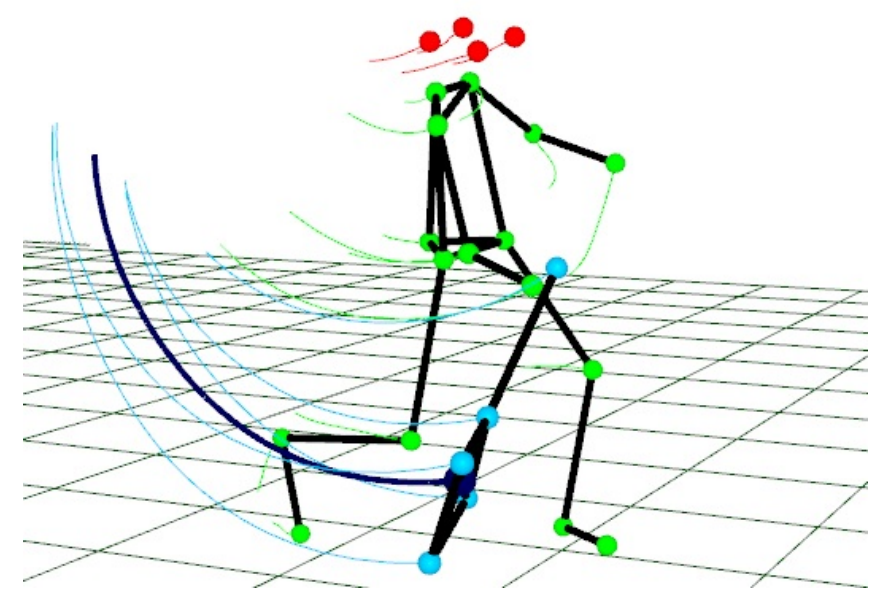

Figure 1. Reflective markers displacement on the athlete. The end of racquet forward swing phase and the beginning of follow through phase in forehand stroke

For the evaluation of cooperation between body segments during the forehand we used the analysis of different joints (ankle, knee, hip, shoulder, elbow, wrist) - each joint activation time in a stroke and a moving velocity. In both groups body segments velocity increases from proximal to distal parts, which is an indicator of a correct stroke movement production in sports biomechanics.

An observation of body segments switching on and cooperation during forehand production allow to describe the body segments interaction in each stroke (an examples Fig. 2 and Fig. 3).

The forehand production in adult athlete (Fig. 1) starts from sequential accelerating segments closer to the ground (ankle - knee), a moment later - a hip and shoulder join the movement. Within practically the same 
time interval an elbow and wrist join the action. The maximum velocity of the segments increases in the sequence of interaction in (from proximal to distal).

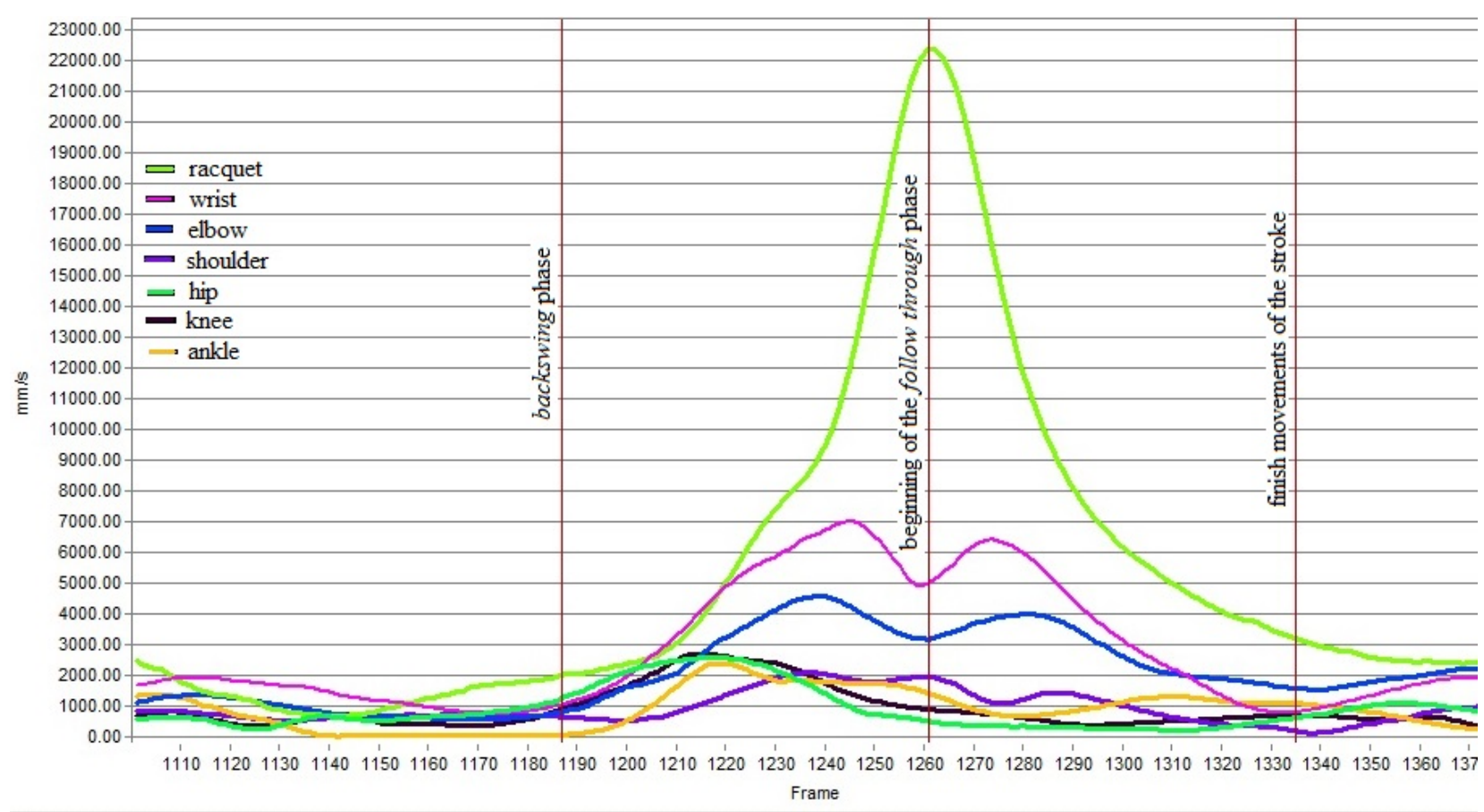

Figure 2. Absolute velocities of the racquet and body segments during the forehand stroke production for adult tennis player

The maximum speed readings of different body segments are reached in different time frames before a moment when the ball is released. Also, we should mention that a new specific characteristic of one athlete's technique was discovered, that is not typical to other adult participants of the experiment and it also differs from those models of stroke movement organization, that have been described in a literature breaking velocity of the proximal body segments occurs in two parts - a moment before racquet touches the ball and continues after the interaction with a ball.

The experimental data shows that young participants also perform the main biomechanical principles of throw-like movements. The quality of correct body segment interaction depends on their technical skills and level of training. In the phase of racquet acceleration (forward swing) we can observe successive inclusion of body segments into action, more pronounced we can observe it for upper body segments (shoulderelbow-wrist), and also sequential braking of the segments velocity before racquet contacts the ball (Fig. 3). 


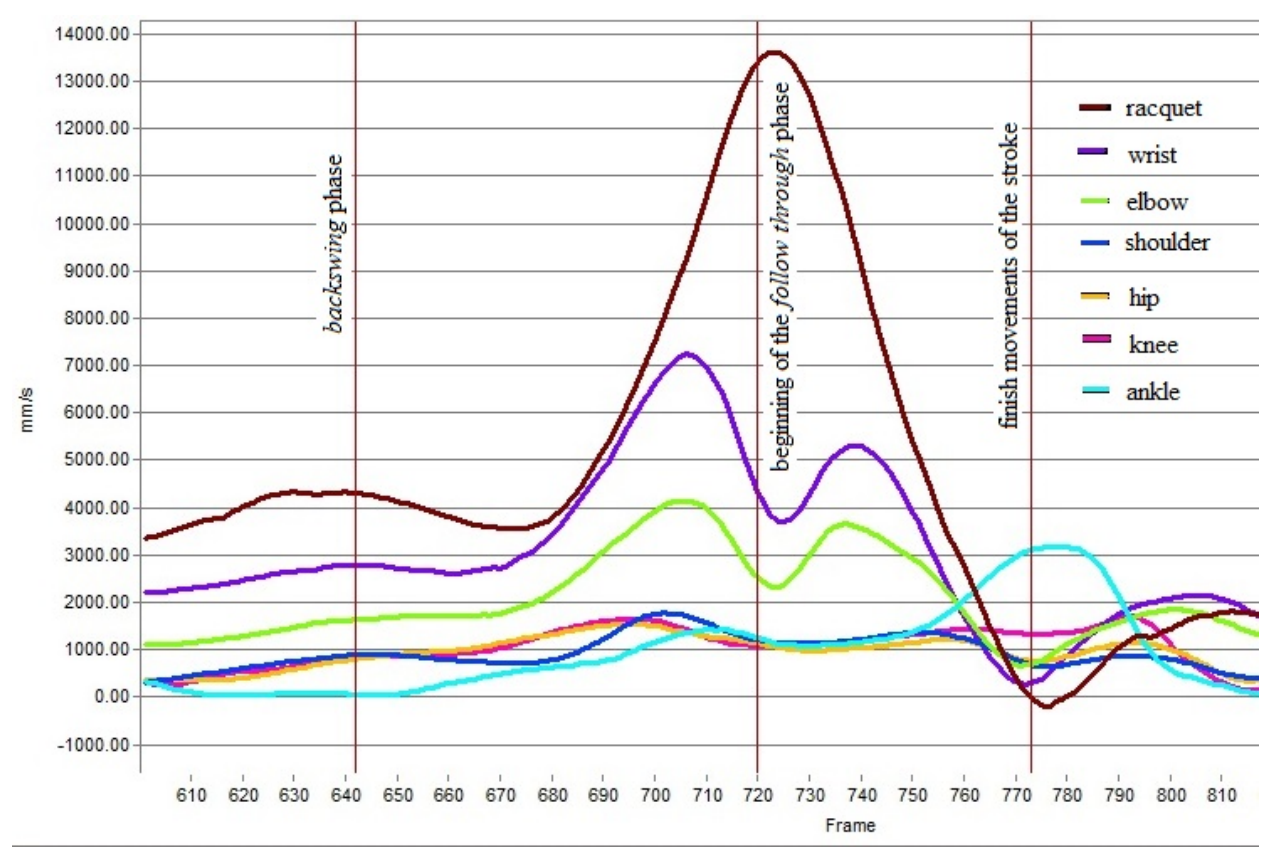

Figure 3. Absolute velocities of the racquet and body segments during the forehand stroke production for young tennis player

The main limitation in young tennis player forehand production is poor lower limb participation during beginning of the movement. An ideal body interaction starts from the ground and impulse is transferring via ankle - knee - hip to shoulder-elbow-wrist-racquet. During young tennis player forehand we see, that movement begins with not sequential, but with simultaneously interaction of knee-hip-shoulder, ankle join doesn't participate, during forward swing phase elbow and wrist velocity peaks reach in the same time these facts are limiting an effect of whip mechanism implementation during stroke production. On the other hand, knee and hip segment is working as one unit (moves with the same velocity and same speed dynamics) during racquet acceleration phase. That testifies that lower body parts act like one solid unit where active interaction between hip and knee zone does not happen, which is considered to be one of the most important indicators of technical skill in throwing when accuracy is highly required

\section{DISCUSSION}

One of the examples that clearly showed individual features of movement organization and differences between athletes, is related to interaction and cooperation of body segments. Rational stroke technique provides that during the backswing tennis player rotates the shoulder zone against stroke direction in a greater angle than hip zone. When the racquet starts to accelerate into the direction of a ball, interaction between body's shoulder zone and hip zone changes in principle - now hip zone turns faster than shoulder zone, when body's proximal segment overtakes distal segment and after a moment distal segment overtakes proximal segment. Fulfilling a stroke in such a way so that one of the most important biomechanical principles is performed - muscle-tendon complex muscle pre-stretch principle. This type of muscle activity in biomechanics is called stretch - shortening cycle, or reversal muscle action (Komi, 1992; Huijing, 1992; Komi \& Nicol, 2000; Prilutsky, 2000). Many specialists consider active interaction between body segments, especially between upper and lower parts of the body as a criteria of an effective technique (Elliott, 2003; Bartonietz, 2000). In technically performed tennis strokes, shoulder zone runs behind hip 
zone, arm after shoulder zone until the final part of the stroke - the contact with a ball (Reinolds, 1996; Иванова, 2008; Sadzek, 2008). Special role in this interaction of body segments play the hip and shoulder zones, as a great number of powerful muscles is involved in this action. Our research supports the opinion of specialists. Maximum x-factor (separation angle between hip and shoulder axis) value in adult tennis players varied around $30^{\circ}$, the average value was $27 \pm 2.2^{\circ}$. The angle value in young tennis players fluctuate around $20^{\circ}$, the average value of the group was $17,8 \pm 1,5^{\circ}$. Active interaction $x$-factor influence on speed of the racquet is also confirmed by results of correlation analysis. In the group of adult players correlation ratio of $\mathrm{x}$-factor was statistically significant and positive $r=0,739$. Statistically significant correlation between $\mathrm{x}$-factor and final speed of racquet in the group of young players was not determined.

Other principle of movement organization which was reviewed in the study was sequential action of muscle groups and body segments. Sequential action of body segments principle in tennis strokes anticipates achievement of three strategies: 1) body segment joining the movement in the proper moment; 2) operation in the direction from proximal to distal body segments; 3 ) active braking of the body segments in the finish of the stroke (Hochmuth, 1964; Dyson, 1978; Lanka, 2003; Winter, 1979; Zatsiorsky et al., 1982; Ivanicevic et.al., 2011). The above consists of two mechanisms - muscle-tendon complex pre-stretch and consecutive acceleration and braking of body segments, in sports literature is called whip technique or whip mechanism (Lanka, 2003; Kopsic Segal, 2003; Ivancevic et al., 2011; Шалманов, 2002).

Adult and young participants of the experiment more or less realize the principle of sequential action of body segments, according to their technical skills and level of training. Faster speed increase is for the segments that are situated farther from the ground. Comparative analysis of graphs of adult and young players' joints and racquet speed-time allowed to determine individual and group differences of organization of movements in young and adult tennis players. Both young and adult tennis players' technique characteristics differ from the correct technique criteria recommended in the specialized literature. For example, racquet reaches maximum speed a moment after the contact with a ball, some athletes practically do not use leg power during the stroke - this is confirmed by ankle and knee joint velocity graphs. In other athlete's stroke hip, elbow and shoulder joint speed reaches maximum practically at the same time with racquet touching the ball. That means that sequential action of body segments from proximal to distal segments is not achieved during the stroke, thus could significantly decreasing efficiency of muscle action. In other examples racquet stroke speed drops and sharply increases right after the stroke, that in no way can influence the speed of a ball. Adult tennis players compared to young players show very rapid increase of the racquet speed, which is achieved by active movement of upper body segments. Obviously the level of athlete's physical training enables rapid acceleration of racquet velocity just with body upper part, and principle of sequential body segment acceleration and sequential braking in strokes without maximum speed practically is not achieved in all of the strokes.

Therefore, besides muscle contraction power we should look for other sources of power added to the racquet and speed increase. One of those is firing catapult biomechanical principle: using the elastic deformation power of muscles, tendons and ligaments, which can be obtained by stretching them at the right moment, other - transmission of the impulse from segments closer to the ground to the upper body parts and further to the hand with racquet in the right time and with sufficient intensity braking the active proximal segments. This could be used in improving efficiency of powerful forehand production in young tennis players. 


\section{CONCLUSIONS}

Adult and young tennis players achieve the biomechanical principle of sequential action of body segments during the forehand stroke production, according to their technical skills and level of training. Adults more effectively achieve muscle-tendon complex pre-stretch principle, which influences a generation of a maximal racquet's velocity - it's significantly higher in adult players' forehands.

\section{ANKNOWLEDGEMENT}

This study is a part of research, financially supported by ESF project "Atbalsts sporta zinātnei" Nr. 2009/0155/1DP/1.1.2.1.2/09/IPIA/VIAA/010.

\section{REFERENCES}

1. Bartonietz, K. (2000). Javelin throwing: an approach to performance. In: Zatciorsky, V.M. (ed.) Biomechanics In Sport Performance Enhancement And Injury Prevention. pp. 401-434, Blackwell Science, LTD, Oxford.

2. Dyson, G. (1978). The mechanics of athletics. London university press, $7^{\text {th }}$ ed., pp.224.

3. Elliott, B. (2003). The development of racquet speed. In: Biomechanics of advanced tennis. ITF, Ltd, pp.33-47.

4. Elliott, B., Mester, J., Kleinõder, H., \& Zengyuan, Y. (2003). Loading and stroke production. In: Biomechanics of advanced tennis. ITF Ltd, pp. 95-107.

5. Hochmuth, G. (1984). Biomechanics of athletic movements. Berlin, Sportverlag, pp.171.

6. Huijing, P.A. (1992). Elastic potential of muscle. In: Komi, P. (ed.) Strength and Power in Sport. Blackwell Sciences, Oxford, pp.197-207.

7. Ivancevic, T., Jovanovic, B., Jovanovic, S., Djukic, M., \& Lukman, A. (2011). A paradigm shift for future tennis. Berlin: Springer, pp.373.

8. Knudson, D., \& Blackwell, J. (2000). Trunk muscle activation in open and square stance tennis forehands. Int J Sports Med, 21, pp.321-324.

9. Knudson, D., \& Elliott, B. (2003). Analysis of advanced stroke production. In: Biomechanics of advanced tennis. ITF Ltd, pp.139-154.

10. Komi, P.V. (1992). Stretch-shortening cycle. In: Komi, P. (ed.) Strength and Power in Sport. Blackwell Sciences, Oxford, pp.169-179.

11. Komi, P.V., \& Nicol, C. (2000). Stretch-shortening cycle of muscle function. In: Zatciorsky, V.M. (ed.) Biomechanics in Sport Performance Enhancement and Injury Prevention. Blackwell Science, LTD, Oxford, pp.87-102.

12. Kopsic Segal, D. (2002). Tennis. Biodynamic system. Indugraf S.A., Argentina, p.p.113.

13. Lanka, J. (2003). Peculiarities of motion organization of different qualification athletes in the final part of shot put. In: New ideas in sport science: current issues and perspectives. Part 1. Warsaw, Poland, pp.143-146.

14. Prilucky, B.I. (2000). Eccentric muscle action in sport and exercise. In: Zatciorsky, V.M. (ed.) Biomechanics in Sport Performance Enhancement and Injury Prevention. Blackwell Science, LTD, Oxford, pp.56-86.

15. Reinold, K. (1995). Step by step biomechanics. Coaching Excellence, 10. pp. 4-5.

16. Rota, S., Hautier, C., Creveaux, T., Champely, S., Guillot, A., \& Rogowski, I. (2002). Relationship between muscle coordination and forehand drive velocity in tennis. J Electromyogr Kines, 22(2), pp.294-300. 
17. Sadzek, T. (2008). Tennis skills. London, Quantum Publishing Ltd, pp.128.

18. Winter, D. (1979). Biomechanics of movement. John Willey and Sons, Toronto, pp.148.

19. Zatsiorsky, V., Lanka, J., \& Shalmanov, A. (1982). Biomechanical analysis of shot put technique. Exercise Sport Sci R, 9, pp. 353-389.

20. Zusa, A., Lanka, J., \& Vagin, A. (2010). Biomechanical analysis of forehand in modern tennis. LASE Journal of Sport Science, 1(1), pp.13-16.

21. Иванова Г.П. (2008). Биомеханика тенниса. Санкт-Петербург, ПИО НГУ им.Лесгафта, 120 с.

22. Шалманов, А. (2002) Методологические основы изучения двигательных действий в спортивной биомеханики. Диссертация дпн. Москва, РГАФК, 262 с. 